\title{
INCIDÊNCIA DE DENGUE EM AMBIENTE COSTEIRO: UMA ANÁLISE DO BAIRRO CIDADE NOVA EM ARACAJUA PARTIR DOS CONDICIONANTES SOCIOAMBIENTAIS
}

\author{
Maria do Socorro Ferreira da Silva ${ }^{(a)}$, Cyntia Sena Santos ${ }^{(b)}$, Flávia Regina Sobral Feitosa ${ }^{(c)}$, \\ Rayane Dejanira Cardoso Santos ${ }^{(\mathrm{d})}$, \\ (a) Departamento de Geografia, Professora Adjunta do Departamento de Geografia/UFS e da Pós-Graduação \\ (PRODEMA e PROF-CIAMB). Pesquisadora do GEOPLAN/CNPq/UFS. E-mail: ms.ferreira.s@ hotmail.com \\ ${ }^{(b)}$ Departamento de Geografia- DGE/Universidade Federal de Sergipe. E-mail:cintiasena05@hotmail.com \\ ${ }^{(c)}$ Mestre pelo PRODEMA/UFS, Universidade Federal de Sergipe. E-mail: flaviareginasf@ gmail.com \\ ${ }^{\text {(d) }}$ Graduada em Geografia pelo Departamento de Geografia (DGE/UFS) e graduanda em Ecologia - \\ Universidade Federal de Sergipe. E-mail: rayanedeja@gmail.com
}

\section{Eixo 3:Climatologia em diferentes níveis escalares: mudanças e variabilidades}

\begin{abstract}
Resumo
O Bairro Cidade Nova apresentou o maior Índice de Infestação Predial (IIP)em Aracaju em 2014 e o segundo em 2015.Esseartigovisa analisar a correlação existente entre os condicionantes socioambientais e o IIP do mosquito Aedes aegypti neste bairro. Para a realização da pesquisa foram realizados: levantamento bibliográfico e documental, pesquisa de campo para identificação, mapeamento e análises dos terrenos baldios;tabulação e interpretações das informações. As análises dos 371 terrenos baldios evidenciaram forte correlação entre a disposição inadequada de resíduos, responsáveis pela acumulação de águadurante período de chuva, contribuindo para a proliferação do Aedes aegypti. É necessárioplanejamento urbano e atuação dos órgãos competentes para melhoria no saneamento básico, ações de Educação Ambiental para a população e políticas públicaspara ordenar o uso do espaço urbano e orientar a comunidadeno combate a proliferação do vetor da doença e evitar os riscos de contrair a doença.
\end{abstract}

Palavras-chaves:risco e vulnerabilidade, Aedes aegypti, chuva, terreno baldio, planejamento urbano.

\section{Introdução}

A dengue é uma das doenças que merece atenção no setor da saúde pública, pois o número de pessoas doentes vem aumentando consideravelmente. Isso ocorre em virtude de seu principal agente transmissor, o mosquito Aedes aegypti, ter encontrado no ambiente urbano local propício para sua reproduçãoe proliferação (COSTA, 2001).

Para Catalão (2012), a dengue é uma doença transmitida por artrópodos, do tipo viral aguda e de início súbita. Transmitida para o ser humano pelo o mosquito do gênero Flavivírus, família Flaviviridae, sendo o Aedes aegypti seu principal vetor em rede global. O mosquito tem costumes e hábitos urbanos, principalmente em lugares onde armazenam água parada para a reprodução do seu vetor. Adapta-se em regiões tropicais e subtropicais entre as latitudes $35^{\circ} \mathrm{N}$ e $35^{\circ} \mathrm{S}$.

Assim, fatores climáticos como temperatura, precipitação pluviométrica, umidade relativa e o ciclo hidrológico possibilitam que esses mosquitos transmissores de doenças se reproduzirem rapidamente e 
se disseminem no ambiente (CONFALONIERI, 2003).Por necessitar desses elementos o mosquito precisa da temperatura propícia para sua proliferação. Para Costa $(2001$, p. 62) "o desenvolvimento do embrião se completa em 48 horas, em condições favoráveis de umidade e temperatura $\left(20^{\circ} \mathrm{C} \mathrm{a} 46^{\circ} \mathrm{C}\right)$ ". Com base nos dados do Ministério da Saúde, no Brasil em 2014 foram registrados 589.107 mil casos de dengue em todo o território nacional, no nordeste esse número foi de 89.935 mil casos, e no Estado de Sergipe 2.246 mil casos da doença (SINAN, 2015).

Em 2014, Aracaju apresentou o Índice de Infestação Predial pelo Aedes aegypti (IIP) de 4,1 considerado o mais alto da capital, e em 2015 apresentou a segunda maior média do IIP com 2,85\%, sendo que a média para capital neste ano foi 1,77\% (ARACAJU, 2014 e 2015).

O armazenamento inadequado de água nos domicílios e a deposição irregular de resíduos sólidos em terrenos baldios no bairro Cidade Nova influenciam diretamente no IIP, pois os recipientes dispostos acumulam água no período de chuva, tornando-se um foco para o mosquito e, consequentemente a proliferação do mosquito Aedes aegypti.

Nesse sentido, osresíduos sólidos dispostos em locais inadequados comprometem o ambiente e a saúde coletiva, pois tornam essas localidades propícias para a proliferação animais transmissores de doenças, como por exemplo, ratos, baratas, moscas, formigas e mosquitos entre eles o Aedes aegypti(PHILIPPI JR.; MALHEIROS, 2005). O crescimento populacional sem planejamento e estrutura adequada de urbanização em ambientes costeiros também acaba propiciando a proliferação de doenças face a dinâmica climática.

As varrições climáticas sazonais nas estações de maior pluviosidade, associadas a outros fatores, como a quantidade de terrenos baldios utilizados pela população para disponibilizarem resíduos sólidos, contribuem para o aumento do número de potenciais criadouros e, consequentemente o aumento da incidência de dengue.

Nesse contexto, este artigoanalisa a correlação existente entre os condicionantes socioambientais e o Índice de Infestação Predial do mosquito Aedes aegypti, no Bairro Cidade Nova em Aracaju no ano 2015. Esse recorte empírico possui uma área de $1,7 \mathrm{~km}^{2}$, com aproximadamente 21.220 habitantes, sendo 11.037 mulheres e 10.183 homens uma média de 3,5 pessoas por domicílios (IBGE, 2010).

\section{Pressupostos teóricos}

A dengue torna-se uma preocupação para a sociedade, pois o número de doentes tem aumentado, tornando-se assim um assunto de alerta para as autoridades de saúde. Segundo Catalão (2012, p. 58 apud OMS, 2009) "o número de pessoas com risco de contrair a doença supera os dois bilhões de pessoas (2/5 da população mundial) e se estima que anualmente ocorrem 50 milhões de casos de dengue". 
No continente Americano, encontra-se Aedes aegypti desde os Estados Unidos da América até o Uruguai, sendo que o único transmissor do vírus na América é o mosquito Aedes aegypti (PNCD, 2002). Dessa maneira,medidas de combate ao vetor vêm sendo estudadas e colocadas em prática para tentar erradicar esse vírusque se desenvolve por metamorfose em quatrofases: ovo, larva, pupa e a fase adulta.

Philippi JR.; Malheiros (2005) afirmaram ainda que a deposição inadequadados resíduos sólidos urbanos possibilita o aumento da proliferação de vetores causadores de algumas patologias. Entre esses vetores está o Aedes aegypti (causador da dengue, febre amarela urbana, zika, dentre outras) que trouxe vários problemas à saúde humana e a qualidade de vida da população. Dessa maneira, é de suma importância a sociedade valorizar os propostos de saneamento do meio, pois a partir deles há a possibilidade de avanço no controle dessas patologias.

Esses fatores expõem a população a riscos de contrair doenças face ao ambiente vulnerável. Nesse aspecto, há necessidade de medidas direcionadas para a prevenção de epidemias a partir do planejamento adequado com base em políticas públicas.

Vale ressaltar que o saneamento básico é "formado por Sistema de Abastecimento de Água Potável, Sistema de Coleta e Tratamento de Águas Residuárias, Sistema de Limpeza Pública e Sistema de Drenagem" (PHILIPPI Jr.; MALHEIROS, 2005, p. 73) que está a serviço do bem estar e saúde da população. Assim, o saneamento básico, de acordo com a lei $\mathrm{n}^{\mathrm{o}} 11.445$, de 5 de janeiro de 2007, capitulo I e II,compreende um conjunto de todas as atividades de cada um desses componentes citados que visa garantiros mais diversos serviços de salubridade ambiental.

Dessa forma, o saneamento básico aliado a ações de Educação Ambiental pode contribuir para que os indivíduos percebam a sua função e participação no seu território de vivência, tornando sujeitos capazes de conservar o ambiente numa perspectiva crítica para cobrar das autoridades os serviços necessários para a diminuição da vulnerabilidade a partir do controle de doenças dentro do território.

Assim, oArt. $2^{0}$ da lei $\mathrm{n}^{0}$ 9.795, de 27 de abril de 1999 ressaltaque a Educação Ambiental é um componente essencial e permanente da educação nacional, devendo estar presente, de forma articulada, em todos os níveis e modalidades do processo educativo, em caráter formal e não-formal.

Dessa maneira, é necessário priorizar ações práticas dessas leis para atender as necessidades da população e incentivar no combate ao mosquito Aedes aegypti de modo que seja possível promover a saúde coletiva no ambiente urbano, especialmente nos bairros periféricos, onde mesmo em cidades litorâneas, são desprovidos de saneamento básico e políticas públicas efetivas.

\section{Procedimentos Metodológicos}

Trata-se de estudo exploratório, quali-quantitativo, onde para coleta de dados foram desenvolvidas as seguintes etapas:levantamento bibliográfico e documental, pesquisa de 
campo, tabulação dos dados, mapeamento, análise e interpretações das informaçõese entrevistas realizadas com os proprietários dos pontos estratégicos.

O levantamento bibliográfico e documental ocorreu mediante consulta e leitura das fontes bibliográficas abordadas na pesquisa as quais estavam relacionadas a: educação ambiental, resíduos sólidos, dengue, políticas públicas. Os documentos usados foram as leis $\mathrm{n}^{\circ} 11.445$, de 5 de janeiro de 2007, que dispõe sobre as diretrizes nacionais sobre o saneamento básico, e a lei $\mathrm{n}^{0} 9.795$, de 27 de abril de 1999, Lei $\mathrm{n}^{\circ} 1.721$, de 18 de julho de 1991, que dispõe o código de limpeza urbana e atividades correlatas Aracaju (SERGIPE, 1991), a Lei no 12.305 de 2 de agosto de 2010, que institui a Política Nacional de Resíduos Sólido, o Programa Nacional de Controle a Dengue (PNCD). Ademais,consultou-se obras, artigos científicos, dissertações e teses.

Para a pesquisa de campoforam necessárias a observação sistemática, a análise dos terrenos baldios de modo que se pudesse identificar os tipos de resíduos dispostos pelos moradores e sua implicação na proliferação da dengue. A pesquisa de campo foi realizada nos dias 19/08/2015, 22/09/2015, 24/09/2015 e 30/09/2015onde visitou-se 371 terrenos baldios cujas coordenadas geográficas foram marcadas com o uso do GPSGarmin.Para identificação dos terrenos baldios utilizou-se um roteiro semiestruturado para caracterização dos pontos de descartes, com seguintes informações do terreno baldio: ausência de muro, presença de vegetação, água parada, tonel, caixa d'água, esgoto, origem dos resíduos sólidos (residencial, construção civil, outros), resíduos dispostos (vasos de plantas, pneu, garrafa, baldes).

Ademais, utilizou-se o registro fotográfico durante a pesquisa e foram feitas visitas em seis pontos estratégicos, considerandoos locais que têm possibilidades de possuir criadouros do mosquito Aedes aegypti no Bairro Cidade Nova, a exemplo de oficinas (concerto de carros e motos), borracharias.

Por fim, os dados foram organizados e tabulados com a utilização do Microsoft Office Excel e o mapeamento dos pontos inadequados de resíduos sólidos (terrenos baldios),com o uso do Sistema de Informação Geográfica (SIG), foi processado no software ArcGis 9.3.

\section{Resultados e Discussão}

O bairro Cidade Nova, localizado na periferia da cidade de Aracaju, encontra-se desprovido de infraestrutura básica que garanta à comunidade a redução dos riscos de adoecimento. $\mathrm{O}$ saneamento básico é uma das principais medidas para manter o ambiente limpo, controlar e prevenir doenças, como por exemplo, a dengue. Entretanto, no bairro pesquisado além da falta de água frequente, que contribui para as pessoas armazenarem água de modo inadequado, e do esgotamento de efluentes doméstico a céu aberto, a coleta regular de resíduos sólidos é precária. A situação se agrava nos períodos de chuvas, pois esses resíduos servirão para o acúmulo de água. 
A coleta de resíduos sólidos ocorre atétrês vezes por semana, mas não é suficiente para manter o bairro limpo, pois faltam contêineres para que as pessoas possam depositar os resíduos gerados. Ressalto que a ausência desses depósitos não deve ser a justificativa para tal disposição em terrenos baldios, mas acaba contribuindo face o baixo nível de sensibilização e conscientização das pessoas. Assim, esses ambientes tornam-se locais propícios para abrigar insetos e roedores e, consequentemente ambiente propício para a proliferação do Aedes aegypti.

Durante as entrevistas realizadas com os proprietários dos pontos estratégicos, os entrevistados ressaltaram que não são trabalhados temas relacionados a Educação Ambiental durante as visitas dos agentes comunitário de saúde, uma vez que os profissionais realizam apenas vistorias.

O trabalho para o controle e a prevenção da dengue é realizado apenas nas visitas domiciliares, o que demanda a necessidade de intensificação de ações práticas e de políticas públicas destinadas para sensibilizar a população.

No tocante ao abastecimento de água dos 53\% moradores entrevistados reforçaram a deficiência, pois há falta com regularidade. Desse modo, a população precisa armazenar água para o consumo utilizando diversas formas, tais como: caixa d'água, galões, baldes, bacias, lavanderias. Essas formas de armazenamento inadequado tornam-se os depósitos propícios para a fêmea depositar seus ovos, e depois transformar em um mosquito adulto com capacidade de contagiar mais de 300 pessoas (PINTO, 2013).

Durante a pesquisa de campo observou a ineficiência do planejamento urbano e do saneamento básico no que concerne à rede de esgoto do bairro em estudo, pois é comum a existência de esgoto a céu aberto, a qual contribui para o acumulo de água parada e contaminada na frente das residências (Figura 01). Essa ocorrência é um problema de saúde pública, pois tornam-se ambientes insalubres que transmitem odores, proporcionam a proliferação de doenças, impedem a circulação das pessoas, além de tornarem-se em criadouros para animais peçonhentos, roedores, e insetos nocivos, como o mosquito Aedes aegypti.

Nesse contexto, evidencia-se a necessidade de aplicabilidade da legislação ambiental no que concerne a fiscalização dos terrenos baldios, os quais são utilizados para a disposição inadequada de resíduos sólidos em terrenos baldios; e, programas efetivos de Educação Ambiental com a comunidade envolvida e uma gestão urbanaeficiente que possa ordenar o uso do território para evitar, nesse caso, a proliferação de doenças que compromete a saúde coletiva.

Nessa ótica, é importante frisar que a aplicação da legislação municipal deve prevê a obrigatoriedade e possibilitar a fiscalização a partir da entrada tanto em imóveis desocupados,como a capina e limpeza de lotes vagos "terrenos baldios" considerados de isco (como foco gerador do vetor), cujos proprietários não se manifestaram após o cumprimento dos trâmites legais, bem como o 


$\begin{aligned} & \text { XVII Simpósio Brasileiro } \\ & \text { de Geografia Fisica Aplicada }\end{aligned}$
$\begin{aligned} & \text { I Congresso Nacional } \\ & \text { de Geografia Física }\end{aligned}$

redirecionamento das ações rotineiras das fiscalizações municipais (sanitária, obras, posturas, limpeza urbana) para verificação de criadouros do vetor bem como medidas necessárias para o combate. Ademais, faz-se necessário a efetivação de medidas punitivas para os proprietários que não cumprem com a responsabilidade prevista na legislação e ajudam a colocar em risco a saúde coletiva (FREITAS, RODRIGUES, ALMEIDA, 2011)

Nesse aspecto, faz-se necessário buscar alternativas no que condiz ao planejamento urbano de modo que possa conter a ocupação e o crescimento desordenado nas cidades (CASSILHA, G. A.; CASSILHA, S. A., 2009), especialmente no que condiz as áreas periféricas.

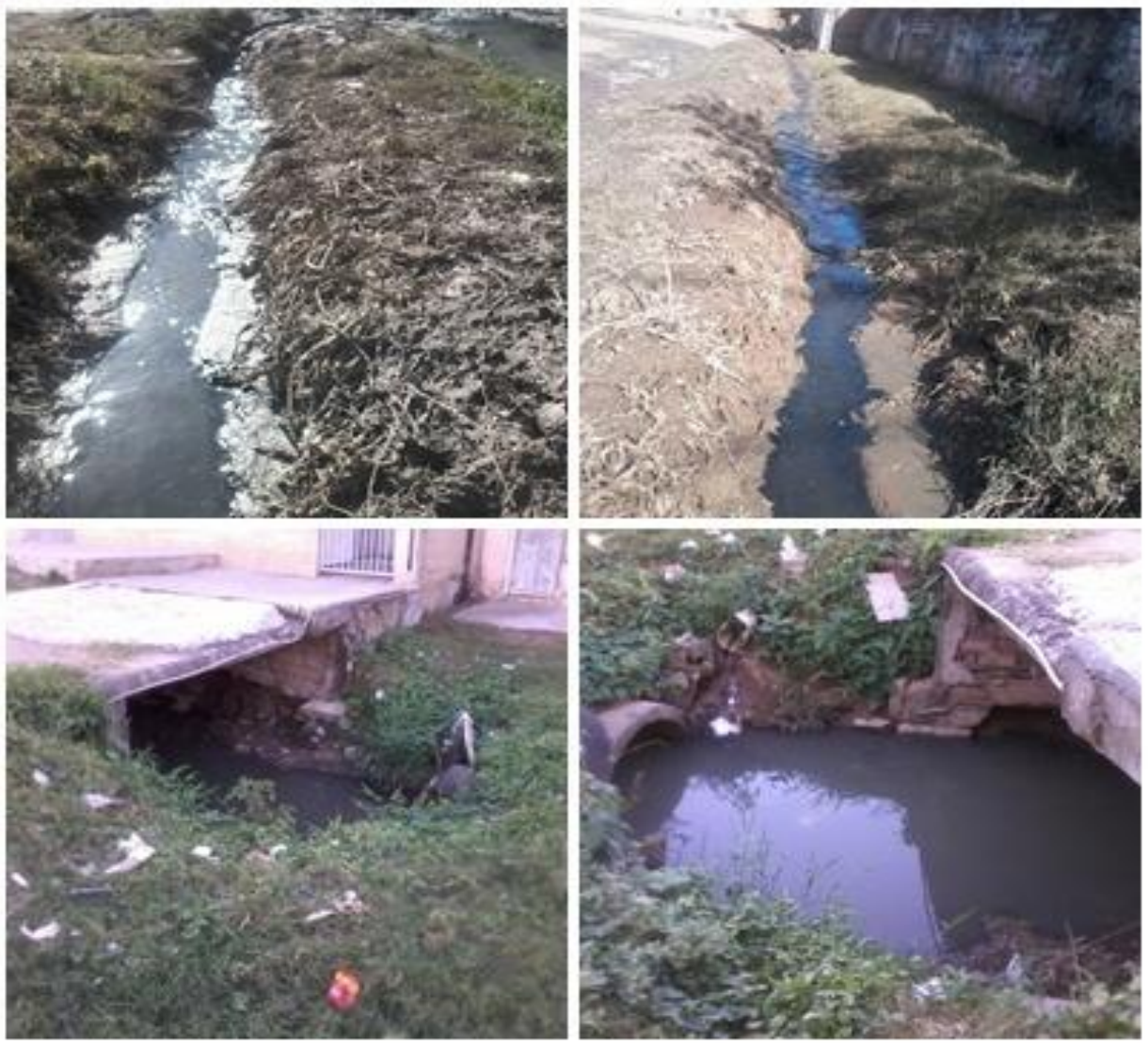

Figura 01: Esgoto a céu aberto, no bairro Cidade Nova em Aracaju Fonte: Pesquisa de campo, 2015

Durante a pesquisa de campo foram visitados 371 terrenos baldios no bairro Cidade Nova e foi perceptível que a população deposita seus resíduos sólidos de modo inadequado nosreferidosambientes (Figura 02).

A pesquisa a campo evidenciou que $89,6 \%$ dos terrenos baldios, no bairro Cidade Nova, possuíam algum tipo de resíduos sólidos (Tabela 01). Para essa análise, considerou-se a classificação quanto a 
origem dos resíduos, estabelecida no Art. 13, parágrafo I, na Política Nacional de Resíduos Sólidos, Lei $n^{\circ} 12.305 / 2010^{1}$. Foram encontrados nos terrenos baldios os seguintes resíduos:

a) resíduos domiciliares: orgânicos (restos de alimentação, folhas de quintal) e inorgânico (embalagens plásticas diversas - bacias, baldes, embalagem de iogurte, tampa de garrafa, lata de refrigerante, copos descartáveis, garrafa PET, cartela de ovos, colchões, dentre outras);

b) resíduos de construção civil: pedaços de madeira, embalagens diversas, restos de construção (blocos, areia, brita, cimento), ferragens, pedaços de telha, dentre outros;

c) resíduos de estabelecimentos comerciais e prestadores de serviços: pneus, sucatas, carcaça de veículos, dentre outros.

d) Outros: colchões, sucatas, carcaça de veículos.

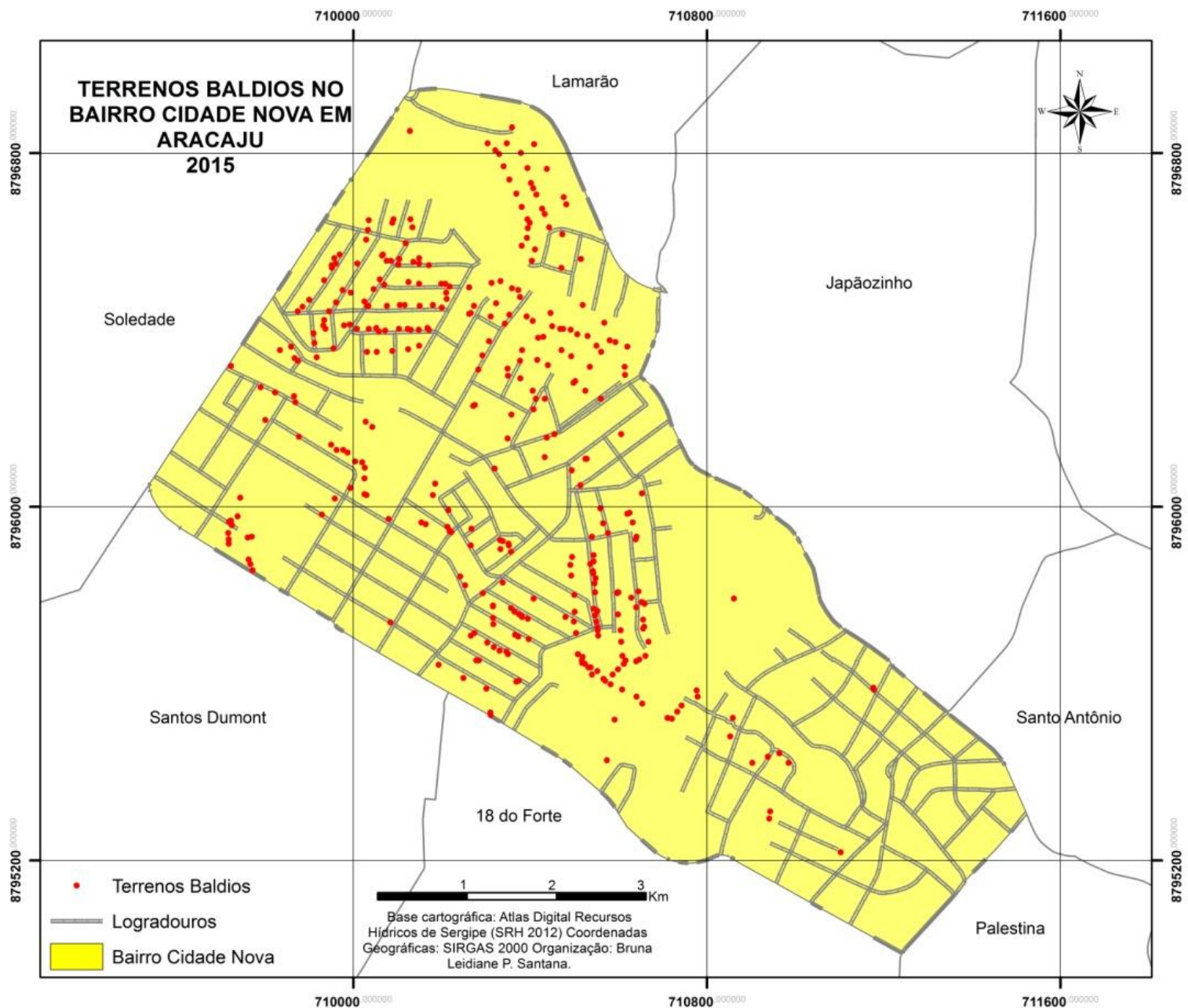

Figura 02: Terrenos baldios localizados no Bairro Cidade Nova, em Aracaju

\footnotetext{
${ }^{1}$ A Política Nacional de Resíduos Sólidos (PNRS) dispõe sobre seus princípios, objetivos e instrumentos, bem como sobre as diretrizes relativas à gestão integrada e ao gerenciamento de resíduos sólidos, incluídos os perigosos, às responsabilidades dos geradores e do poder público e aos instrumentos econômicos aplicáveis (BRASIL, 2010).
} 


\section{OS DESAFIOS DA GEOGRAFIA FÍSICA NA FRONTEIRA DO CONHECIMENTO Instituto de Geociências - Unicamp Campinas - SP \\ 28 de Junho à 02 de Julho de 2017}

Fonte: Pesquisa de campo, 2015

Tabela 01: Situação dos terrenos baldios quanto à disposição inadequada de resíduos sólidos urbanos no bairro Cidade Nova, em Aracaju 2015

\begin{tabular}{|l|c|}
\hline \multicolumn{1}{|c|}{ Situação do terreno } & Quantidade \\
\hline Terrenossemresíduossólidos & 62 \\
\hline Resíduossólidosdomiciliares & 247 \\
\hline Resíduos de Construção Civil & 97 \\
\hline Recipientes capazes de armazenar água ${ }^{2}$ & 103 \\
\hline Outros & 86 \\
\hline
\end{tabular}

Fonte: Pesquisa de campo, 2015

Conforme a Lei 1.721/ 199, que dispões sobre Código de limpeza urbana e atividades correlatas,

"é proibido lançar ou propiciar a colocação lixo, entulhos, animais mortos ou galhadosem terreno baldios ou em qualquer imóvel, edificado ou não, público ou privado, bem como encostas, rios, valas, valões, canais, praias, manguezais, ou quaisquer outros locais não autorizados pela Prefeitura Municipal de Aracaju, ou que prejudiquem ou possam vir a prejudicar os serviços de limpeza urbana de qualquer forma à saúde, ao bem estar ou ao meio ambiente, ou ainda propicie a proliferação de vetores, ratos ou ratazanas" (ARACAJU, 1991).

A situação do bairro reflete a inaplicabilidade da legislação em vigor em virtude da ausência na fiscalização. Os resíduos sólidos depositados inadequadamente nos terrenos baldios podem gerar problemas a saúde pública, pois essas localidades se tornam ambientes propícios para proliferação animais que podem transmitir doenças, como a leptospirose, transmitida pela urina do rato, a disenteria ou diarreia transmitida por moscas e mosquitos, principalmente o Aedes aegypti, o qual encontra nesses ambientes recipientes que acumulam água para depositar seus ovos.Desse modo, a população local fica mais vulnerável para contrair essa doença.

Outro fator que contribui para a disposição inadequada de resíduos sólidos urbanos nos terrenos baldios foi a ausência cercas ou muros (Figura 03), tornando-os mais acessíveis essa disposição.

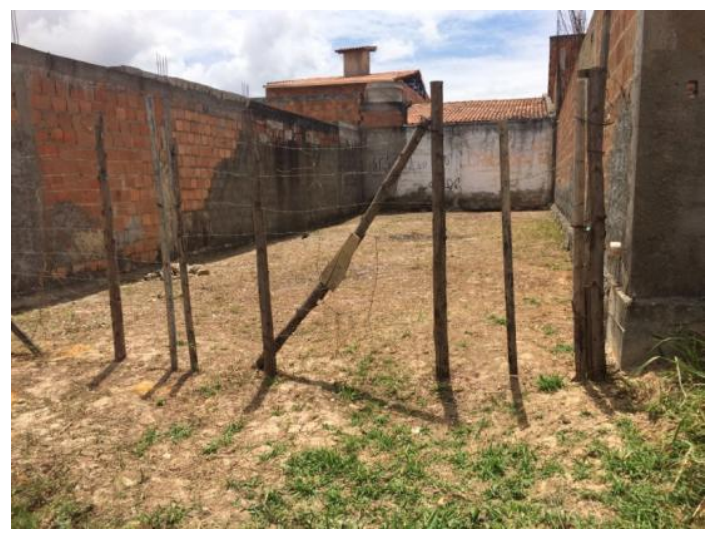

Figura 03: Terreno cercado no Bairro Cidade Nova em Aracaju

Fonte: Pesquisa de campo, 2015

\footnotetext{
${ }^{2}$ Bacias, baldes, garrafas de vidro, garrafa PET, pneus, embalagem de iogurte, tampa de garrafa, tampas de garrafa.
} 
Nesse aspecto, verificouque $82,5 \%$ dos terrenos não estavam cercados ou murados (Tabela 02). Vale destacar que, boa parte dos terrenos cercados ou murados, permaneciam sem resíduos, poisdificulta e/ou impede o acesso das pessoas.

Tabela 02: Características dos terrenos baldios no bairro Cidade Nova, em Aracaju, em 2015

\begin{tabular}{|c|c|c|c|c|c|c|c|c|c|c|c|}
\hline \multicolumn{4}{|c|}{ Muro/ Cerca } & \multicolumn{4}{c|}{ Vegetação } & \multicolumn{4}{c|}{ ÁguaParada } \\
\hline \multicolumn{2}{|c|}{ Sim } & \multicolumn{2}{|c|}{ Não } & \multicolumn{2}{c|}{ Sim } & \multicolumn{2}{c|}{ Não } & \multicolumn{3}{|c|}{ Sim } & \multicolumn{3}{|c|}{ Não } \\
\hline $\mathrm{N}^{\mathbf{o}}$ & $\%$ & $\mathrm{~N}^{\mathbf{0}}$ & $\%$ & $\mathrm{~N}^{\mathbf{0}}$ & $\%$ & $\mathrm{~N}^{\circ}$ & $\%$ & $\mathrm{~N}^{\circ}$ & $\%$ & $\mathrm{~N}^{\mathbf{o}}$ & $\%$ \\
\hline 65 & $17 \%$ & 306 & $82,5 \%$ & 361 & $97,3 \%$ & 10 & 2,7 & 26 & 7,0 & 345 & 93,0 \\
\hline
\end{tabular}

Fonte: Pesquisa de campo, 2015.

Outra variável observada na pesquisa de campo foi à presença de vegetação em 97,3\% dos terrenos baldios no bairro (Tabela 02), pois se percebeu que boa parte de terrenos com tal característica possuía resíduos com acumulo de água. Esses materiais ficam cobertos pela vegetação e acabam se tornando potenciais criadouros do Aedes aegypti. Além disso, o porte da vegetação dificulta o acesso dos agentes de endemias nas vistorias para verificação de focos de dengue no local. Ademais, há riscos de encontrar animais peçonhentos.

A pesquisa também revelou que $7 \%$ terrenos tinha recipientes com água parada tornando-se um local propício para a fêmea do mosquito depositar os ovos, e 4,0\% deles tinham alicerceis de residências iniciados e abandonados (Tabela 03). Esse fator também propicia espaços para o acúmulo de água, principalmente nos períodos chuvosos.

Tabela 03: Características dos terrenos baldios, no bairro Cidade Nova em Aracaju, em 2015

\begin{tabular}{|c|c|c|c|c|c|c|c|c|c|c|c|}
\hline \multicolumn{4}{|c|}{ Tonel/caixa d' água } & \multicolumn{4}{c|}{ Esgoto a céuaberto } & \multicolumn{4}{c|}{ Construção - alicerce } \\
\hline \multicolumn{2}{|c|}{ Sim } & \multicolumn{2}{|c|}{ Não } & \multicolumn{2}{c|}{ Sim } & \multicolumn{2}{c|}{ Não } & \multicolumn{2}{c|}{ Sim } & \multicolumn{2}{c|}{ Não } \\
\hline $\mathrm{N}^{\mathbf{o}}$ & $\%$ & $\mathrm{~N}^{\mathbf{o}}$ & $\%$ & $\mathrm{~N}^{\mathbf{o}}$ & $\%$ & $\mathrm{~N}^{\mathbf{o}}$ & $\%$ & $\mathrm{~N}^{\mathrm{o}}$ & $\%$ & $\mathrm{~N}^{\mathbf{0}}$ & $\%$ \\
\hline 02 & 0,5 & 369 & 99,5 & 33 & 8,9 & 336 & 91,1 & 15 & 4,0 & 359 & 96 \\
\hline
\end{tabular}

Fonte: Pesquisa de campo, 2015.

Vale ressaltar que no período da pesquisa a campo (dias 19/08/2015, 22/09/2015, 24/09/2015 e 30/09/2015)havia baixo índice ou ausência de precipitação pluviométrica em Aracaju (Figura 04) e mesmo assim ainda haviam recipientes com água acumulada. Além disso, em função do porte da vegetação e riscos de animais peçonhentos, não foi possível entrar em parte dos terrenos. 


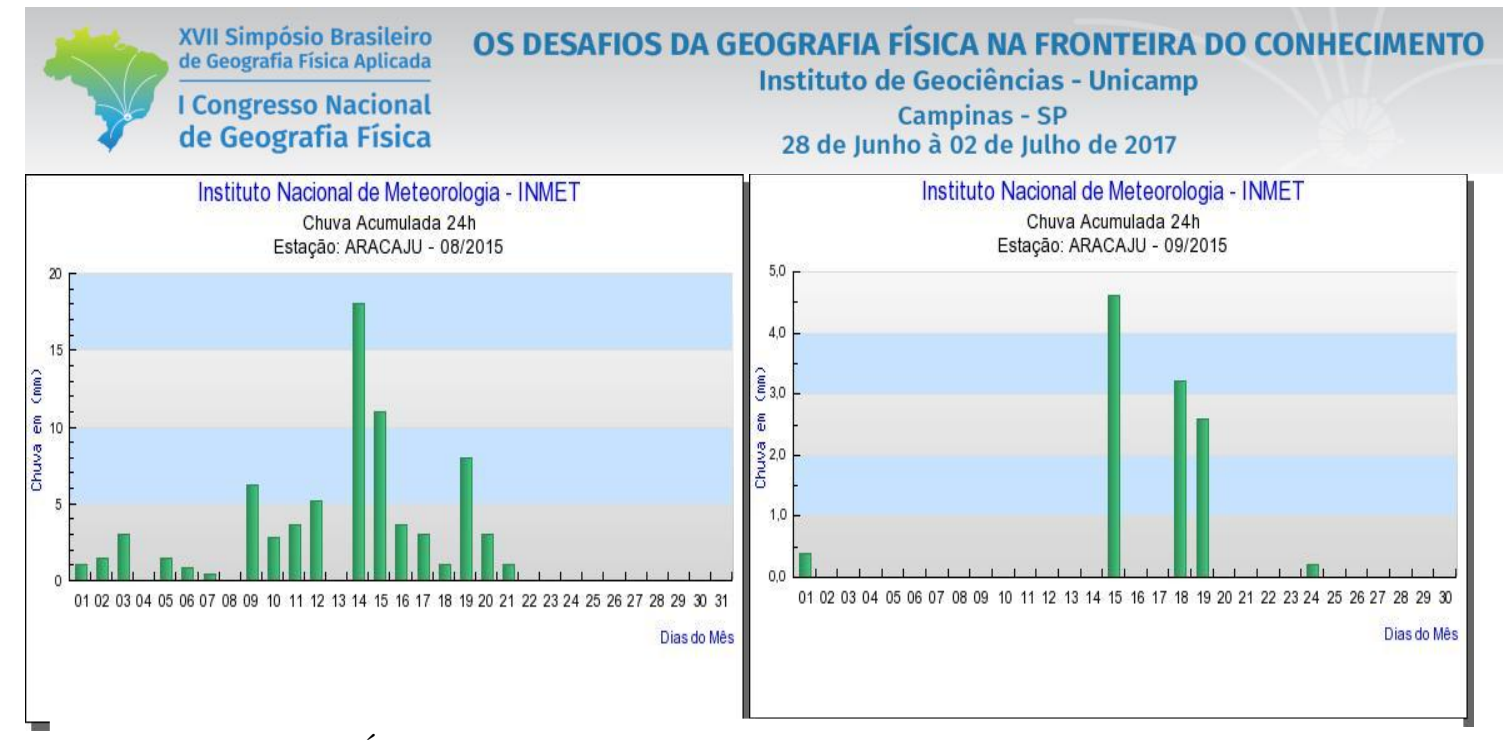

Figura04: Índice Pluviométrico do mês de Agosto e Setembro Aracaju, 2015

Fonte: INMET, 2015.

O estudo do bairro Cidade Nova em Aracaju, proporcionou analisar a influência dos resíduos sólidos dispostos de modo inadequado nos terrenos baldios e certamente, tornam-se criadouros para o mosquito e proliferação da dengue após o período de chuva. Diante dos resultados, ressalta-se a ineficiência do saneamento básico. Essas informações evidenciam a ausência serviços de qualidade para a comunidade e de políticas pública e ações capazes de sensibilizar e conscientizar a população sobre o seu papel no controle da dengue.

Faz necessário a análise do território para conhecer as necessidades da população, especialmente no tocante a saúde coletiva em zonas periférica, cuja população está mais vulnerável as doenças transmitidas, especialmente por artrópodes, como o mosquito Aedes aegypti. A ocorrência de doenças está associada diretamente a ineficiência da infraestrutura e saneamento básico, como por exemplo, rede esgoto, coleta de resíduos sólidos, abastecimento de água, dentre outros, cujos fatores influenciam para o aumento do IIP na escala local.

\section{Considerações Finais}

No bairro Cidade Nova, alguns fatores estão contribuindo para o aumento do IIP, tais como: a urbanização desordenada, a ineficiência do saneamento básico, a disposição inadequada de resíduos sólidos em terrenos baldios, a ausência de políticas públicas, a falta de sensibilização da população, a deficiência na fiscalização pelos poder público local, dentre outros.

As análises evidenciaram que $89,6 \%$ dos terrenos baldios analisados possuem algum tipo resíduo sólido que podem servir de criadouro para a reprodução do mosquito Aedes aegypti, o que efetivamente torna a população mais vulnerável aos riscos de contrair a doença. Dentre os fatores que contribuem para a disposição inadequada de resíduos sólidos nos terrenos baldios pode-se citar a falta de cerca ou muro nesses ambientes. 
A realização da coleta regular de resíduos sólidos até três vezes por semana, no bairro Cidade Nova, não é suficiente para atender as necessidades da população local. Entretanto, esse tipo de ação não deve se justificar somente pela ausência de programas de educação ambiental.

A ineficiência do saneamento básico, quanto se trata de esgoto a céu aberto também, é outro fator que contribui para a proliferação da dengue e de outras enfermidades no bairro em estudo, pois possibilita o acumulo de água parada mesmo após o período de chuvas.

Em virtude dos fatos mencionados é de suma importância o mapeamento dos terrenos baldios no bairro, a partir do SIG, pois fornece suporte para visualizar espacialmente o território, permitindo criar estratégias para que haja maior controle e manutenção desses ambientes. Ademais, a partir da análise da localização geográfica dos terrenos, considerando as ruas que possuem uma maior quantidade de terrenos baldios, é possível identificar os terrenos mais próximos as residências para que esses sejam priorizados na busca por possíveis soluções, especialmente no que condiz a limpeza e o controle da água acumulada e os efetivos riscos de adoecimento.

É de suma relevância que a população local seja sensibilizada e conscientizada sobre o seu papel enquanto geradora de resíduos. Entretanto, cabe ao poder público buscar medidas socioambientais para a efetivação de projetos e ações direcionadas para a Educação Ambiental. Além do mais, utilizar os meios de comunicação como rádio, TV, jornais impressos, panfletos para auxiliar nas campanhas de prevenção e Educação Ambiental em prol de minimizar os problemas que afetam a saúde coletiva. Outra estratégia que pode ser associada, é a socialização de informações nas associações, repartições públicas e igrejas para a divulgação e/ou realização de palestras, cursos, seminários e atividades práticas que sensibilize a população sobre a sua importância no combate ao mosquito e aos riscos que a doença traz para o ser humano.Outra estratégia é trabalhar em parceria com a escola, pois é o local frequentado por crianças e jovens, as quais podem auxiliar no combate ao mosquito, face ao aprendizado que pode ser repassado para seus familiares, vizinhos e amigos.

Ademais, é fundamental que haja fiscalização bem como punições severas para os proprietários que não mantem a limpeza dos imóveis (lotes vazios).

\section{Bibliografia}

ARACAJU. Lei no 721/1991. Código de limpeza urbana e atividades correlatas. Aracaju-SE, 18 jul. 1991.

BRASIL. Lei $\mathbf{n}^{0}$ 11.445, de 5 de janeiro de 2007.Estabelece diretrizes nacionais para o saneamento básico. Diário Oficial da União. Brasília-DF, 5 jan. 2007. Disponível em: <http://www.planalto.gov.br/ccivil_03/_ato2007-2010/2007/lei/111445.htm>. Acesso em 15 dez. 2015.

BRASIL. Lei $\mathbf{n}^{\mathbf{0}}$ 12.305, de 2 de agosto de 2010. Institui a Política nacional de resíduos sólidos. Brasília-DF, 2 ago. 2010. Disponível em: < http://www.planalto.gov.br/ccivil_03/_ato2007-2010/2010/lei/112305.htm >. Acesso em 14 jul. 2016. 
BRASIL. Lei no 9.795, de 27 de abril de 1999. Dispõe sobre a educação ambiental, institui a Política Nacional de Educação Ambiental e dá outras providências. Diário Oficial da União, Brasília, DF, 27 abr. 1999. Disponível em: 〈http://www.planalto.gov.br/ccivil_03/leis/19795.htm〉. Acesso em 15 dez. 2015.

CASSIlHA, A. G.; CASSILHA, S. A. Planejamento Urbano e Meio Ambiente. Curitiba: IESDE Brasil S.A., 2009.

CATALÃO, R. Dengue no Brasil uma abordagem geográfica na escala nacional. São Paulo: Cultura Acadêmica, 2012.

CONFALONIERI, C, E, U. Variabilidade climática, vulnerabilidade social e saúde no Brasil. Terra Livre. São Paulo. V. I, n. 20, p. 193-204, jan/jul. 2003.

COSTA, R, A, M.; A ocorrência do Aedes Aegypti na região noroeste do Paraná: um estudo sobre a epidemia da dengue em Paranavaí - 1999, na perspectiva da Geografia médica. Dissertação (Mestrado em Geografia) Universidade Estadual Paulista, Presidente Prudente, 2001. 173 f.

FREITAS, R. M.; RODRIGUES, C. S.; ALMEIDA, M. C. M. 2011. Estratégia Intersetorial para o Controle da Dengue em Belo Horizonte (Minas Gerais), Brasil. Saúde Soc. v. 20, n. 3. São Paulo, 2011. p.773-785.

FUNASA. Programa Nacional de Controle a Dengue. Brasília, 2002.

IBGE. Censo Demográfico. Rio de Janeiro, 2010.

INMET - Instituto Nacional de Meteorologia. Tempo/Gráficos - 2015. Disponível em: <http://www.inmet.gov.br/sim/abre_graficos.php> Acesso em 14 de fevereiro de 2017.

PHILIPPI JR, A.; MALHEIROS, T. F. Saúde Ambiental e Desenvolvimento. In: PHILIPPI JR, A.; PELICIONI, M.C.F. Educação Ambiental e Sustentabilidade. São Paulo: Monole, 2005.

PINTO, H, P. Dengue: situação ambiental e dimensão geográfica em 2011, 2012 e 2013. Dissertação (Mestrado em Engenharia de Saúde Pública e Desenvolvimento Sustentável). Universidade Federal do Espírito Santo, Centro Tecnológico, Vila Velha, 2013. 137 f.

SINAN. Caso de dengue Brasil, Grandes Regiões e Unidade Federadas 1990 a 2014. SES/SINAN, 2014. Disponível em: 〈http://portalsaude.saude.gov.br/index.php/situacao-epidemiologica-dados-dengue>. Acessos em 15 de janeiro de 2016. 